\title{
4 The Social Enterprise Phenomenon in the Georgian Context
}

\author{
Maya Giorbelidze
}

\section{Introduction}

People mean many different things when referring to "social enterprise" (SE) in Georgia, and a clear common definition is lacking; however, many experts agree on the crucial need for such a definition. The term "social enterprise" has recently gained popularity, but the concept itself is not a new one, and it is important to look at some of the antecedents of the current idea to understand it better. There is a strong belief in the idea that enterprises operating within a free market are socially beneficial, as businesses provide jobs, create wealth that is shared within society and generate revenue for the governments; the market, operating within a strong framework of state regulation and rule setting, enables this to happen most efficiently through competition, which ensures that the strongest enterprises grow and develop. Adam Smith expressed the idea that an individual pursuing his/her own self-interest also tends to promote the good of the community as a whole, perhaps even more so than those actions nominally born of higher motives: "By pursuing his own interest, he frequently promotes that of the society more effectually than when he really intends to promote it" (Smith 1776).

\section{Historical Context}

The historical context of SE development in Georgia has deep roots and can be linked with the period of trade development in the country in the 18th century. The economic conditions during that period revealed the need to join public and private equities to produce goods and services and reduce economic risks, and the evolution of trade relations led to the establishment of small merchant unions. These "union-type formations" can be identified as the first seeds of social entrepreneurship and collective capital development.

This period was followed by the Soviet era; in the early 1920s, the individual economic risk component was completely removed. The vulnerability of the owners of agricultural resources was "taken over" 
by agricultural cooperatives-the "collective farms". Yet, although the Soviet agrarian reform succeeded in eliminating individual economic risks, it also failed in several ways, as it was undermined by several indirect and spill-over effects, such as low-quality management, waste and robbery of resources and products, lack of basic food, foreign debts and falsification of statistical information. Although "social” enterprises were created, the non-existence of the individual sphere (with its concomitant private property and risks) resulted in a total lack of motivation.

Georgia was among the first former Socialist republics to implement a large-scale land redistribution plan. This land redistribution, which started in 1992, resulted in hundreds of thousands of people becoming small landowners; they replaced the large-scale collectives and production cooperatives (sovkhozes and kolkhozes) of the Soviet period (Lerman and Sedik 2014), which can be considered to a limited extent as predecessors of social enterprises. The main purpose of this land privatisation process was to help a large part of the population survive the extremely hard times that followed the dissolution of the Soviet Union. ${ }^{1}$ The 1990s were indeed a difficult period for Georgia, and the agricultural sector was not spared. Agricultural production decreased by $11 \%$ annually between 1991 and 2000; even after this period, the sector's recovery was very modest, lagging behind the rest of the economy, with a growth rate of $0.6 \%$ per year between 2001 and 2012 (Millns 2013).

In the late 1990s, a new type of social entrepreneurship started to emerge in Georgia, which mainly focused on supporting the poorer layers of society-conflict-affected and socially vulnerable people; these new initiatives were fostered by socially oriented businesses.

All in all, the term "social enterprise" remains a very recent concept in Georgia. Interest in the concept was fuelled by the shift that happened in international donors' activities. Indeed, because the country achieved middle-income status, international donors' grant funding to NGOs started to decrease, and this led many Georgian NGOs to look for alternative funding sources; many turned to the sale of goods and services within an SE framework. Social entrepreneurship thus corresponds to dynamics which are not totally new in Georgia, but the actors involved in these activities are. One could even argue that the current development corresponds mainly to a redefinition of business types rather than to the invention of new types-which makes sense, as SE-related concepts seem to generate increasing interest among donors and can be considered as a possibility to attract additional financial resources.

\section{Legislative Context}

When developing a legal framework for social enterprise, it is important to first determine what is regarded as a social enterprise and what the characteristics of such an initiative are. On the basis of corporate law, it 
may be said that, despite the diversity of legal definitions among countries, there are fundamental features of social enterprise that are more or less recognised in all legal systems. The study requested by the European Parliament on a European statute for social and solidarity-based enterprises ${ }^{2}$ states that, beyond individual differences and peculiarities, a primary condition for an adequate legal framework pertaining to social enterprises is that it recognises and specifically regulates them under organisational law. Indeed, ad hoc legislation on social enterprise offers several advantages to social entrepreneurs and fosters the growth and development of this particular type of business organisation. It makes it possible to reserve the use of the legal denomination of social enterprise for real social enterprises, and allows social entrepreneurs to signal the terms and conditions that their organisations offer to stakeholders and to give credence to their commitment not to change such terms and conditions. The Georgian reality is aligned with the acquis in most of the areas, even though it can also differ on some aspects.

- The EU definition states that a social enterprise is a legal entity based on private law, and that it is independent from state and public governing bodies. In Georgia, there is no specific legal form for social enterprises, and these are registered under various legal forms, but they do meet these two conditions.

- According to the EU definition, social enterprises have an exclusive or at least a leading goal to serve the community or community interests. Georgian initiatives do aim to serve the community; community interests are seen as a key priority, and all activities are oriented in this direction.

- The EU definition states that a social enterprise is subject to full or at least partial restriction on the distribution of profits; more generally, specific rules regulate the distribution of income and profits during the enterprise's existence and in case of liquidation or if the entrepreneur loses his/her qualification of "social entrepreneur". Since, in Georgia, in a large majority of cases, social enterprises are registered as non-profit organisations, this provision is usually de facto respected.

- According to the EU definition, a social enterprise should take socially useful actions; such actions could include labour-integration activities for vulnerable groups. In Georgia, social enterprises are working with people with disabilities, internally displaced persons (IDPs), socially vulnerable people, etc. A large share of the activities carried out by social enterprises is directed towards producing goods and services, which is also in line with the EU definition.

Due to a gap in Georgian legislation, most of the social enterprises are currently being established in the country as non-profit organisations. 
A few social enterprises choose to be established as limited-liability companies (LLCs), which is also a possibility. Recently, a coalition of local and international NGOs started lobbying for the adoption of specific legislation that would enable social enterprises to register as such; this is currently under discussion in the Parliament.

\section{Analysis of Current Operating Practices of Social Enterprises in Georgia}

In order to assess the challenges and opportunities that social enterprises currently operating in Georgia are facing, we designed and carried out a qualitative survey. In a first stage, case study was identified as the best strategy for the study; then the processes of data collection and interpretation were planned. Before fieldwork began, a case-study protocol was constructed to establish the instruments to be used for evidence gathering and analysis. The case-study protocol provided guidance and ensured consistency in the research process.

In order to identify trends, a cross-case analysis (case comparison) was performed by inspecting cases and forming groups-or "clusters"- that shared similar configuration patterns or were similar with respect to some dimensions (Ghauri 2004). In addition to case comparison based on pattern seeking, clustering and matrices were also used. Through these various techniques, which can also be used individually but were combined here to tend towards a flawless analysis process, four clusters were identified. Ongoing reduction of data was performed to increase the focus on key elements; less relevant evidence was put aside, while the most relevant elements were coded and classified. Graphical tools, such as matrices and tables, were used to illustrate the magnitude and relationships of constructs and phenomena identified in the analysis.

Initially, we contacted the Centre for Strategic Research and Development of Georgia (CSRDG), which operates a social-entrepreneurship centre. The Centre provided a list of 102 social enterprises, among which 20 enterprises were selected through random sampling. The sampling criteria included the fields of activity, size and geographical location of the enterprises. This chapter presents the findings that resulted from the analysis of the 20 selected cases.

Because case studies are usually about human behaviour and social processes, Yin (1998) regards interviews as one of the most important sources of case-study information. For the investigation, personal interviews were conducted with top-level managers of the 20 selected social enterprises. Interviews were semi-structured: they were controlled through the use of an interview guide listing the topic areas to be covered in the discussion. The guidelines did not only provide a general structure for the discussion, but they also made it possible to ensure that the same questions were addressed by each informant. The set of topics and 
questions was based on the questionnaire developed during the casestudy approach and on the preliminary conceptual framework and initial propositions. However, the interview process was also flexible, to the extent that, when areas of investigation that had not been originally foreseen or planned appeared to provide insight into the area of investigation, adjustments were made to the study: questions were added to probe particular themes or issues which had emerged from previous cases.

\subsection{Research Findings}

As underlined earlier, there is currently no unified approach towards social entrepreneurship in Georgia, and many organisations define the term in their own way. In order to ensure comparability of data across the whole research process, all key informants were asked to share their perception of the term "social enterprise". It is interesting to note that a social enterprise is generally defined by the respondents as an enterprise operating according to business principles but with primary social objectives.

Particularly noteworthy is the fact that the term "social enterprise" is perceived in a similar way by public, private for-profit and civil-society organisations. However, as already mentioned, there is no unified database gathering information on all types of social enterprise as it is difficult to identify "social enterprises", and such identification is currently done only in a subjective way.

\section{Specific Constraints}

The study demonstrated that operating a social enterprise is even harder than managing a for-profit business. In particular, the following constraints were highlighted by the respondents:

- Lack of access to finance: due to the fact that there is no proper definition of social enterprise in the legislation, social enterprises operate under various legal forms, and those registered as NGOs cannot access credit. Indeed, based on the regulations of commercial banks operating in Georgia, NGOs are not eligible for loans. However, an initiative launched by international NGOs in partnership with a commercial bank considers making loans available to social enterprises in that particular financial institution-an evolution that would require an amendment of the law.

- Absence of specific legal status and legislation: nowadays, in the absence of specific legislation that would define and identify an SE legal form, social enterprises self-identify as such but officially register under various legal forms. As mentioned earlier, the majority of social enterprises operating in Georgia are registered non-profit 


\section{Giorbelidze}

organisations. The rationale behind such choice is that the vast majority of social enterprises are established with financial grants, and the other most commonly encountered legal form under which social enterprises can operate-namely that of limited-liability company-is not authorised to receive grant money as per Georgian legislation. As for the agricultural cooperatives mentioned in Section 1, they are, quite logically, registered under the legal form of cooperative. Gaps in legislation also lead to confusion in financial reporting and accounting. The entrepreneurs surveyed indicated that they had to consult with many different agencies, lawyers or financial specialists (sometimes to no avail) in order to ensure proper taxation by the state. The social entrepreneurs surveyed nevertheless considered that no separate legislative form was needed, and that a definition of "social enterprise" should simply be added in existing laws.

- Gap in knowledge and skills: along with the lack of specific legislation, the low level of knowledge of business-management practices among social entrepreneurs was outlined as a challenge. All participants indicated that, due to the fact that the majority of them had a background in the field of non-governmental organisations (NGOs), they lacked experience/tools of business management.

- Lack of guidance and support: the vast majority of the social enterprises surveyed outlined that they had received almost no guidance at the inception stage. There is no unified information providing direction and guidance for new social entrepreneurs; the respondents stated that the existence of a manual/guidebook for operating a social enterprise would have been helpful.

- Low awareness of the SE phenomenon: as evidenced by the survey, social enterprises' clients are not aware of the SE phenomenon. As a respondent put it: "The population does not know anything about social entrepreneurship and the situation is the same in the capital and in rural areas. Only those who have attended training have a basic knowledge of the subject". Respondents highlighted this as a constraint for the initiatives' development; they suggested that awareness-raising campaigns be organised among the general public, and that state and private-sector representatives be targeted as well, with a view to enhancing their engagement in favour of social enterprise.

To summarise, social enterprises operating in Georgia appear to experience the same type of constraints as social enterprises in many other countries. Access to finance, enhanced skills and capacities and legislative support, coupled with encouragement from the general public, are crucial for the successful operation of inclusive businesses, thus enabling them to make a social impact on a larger scale. 


\section{Social Mission and Impact of Social Enterprises}

The research demonstrated that the social enterprises operating in Georgia typically support the training and employment of vulnerable groups of the population (young people, the elderly, rural youth), which is expected to reduce internal migration.

While social enterprises balance social and financial objectives, the social mission is usually prioritised, although several cases are known where entrepreneurs were primarily guided by financial goals to ensure the sustainability of the enterprise.

The research demonstrated that none of the surveyed social enterprises assessed its social impact; however, they did outline the importance and urgency of such impact assessment.

The participating enterprises aimed to meet the basic needs of their target population; in other terms, they focused on the first level of Maslow's hierarchy of needs. They attempted to create learning and employment opportunities for their customers in order to enable them to meet their basic needs.

\section{On-line Survey}

In order to further justify and strengthen the evidence generated by the case studies, an on-line survey was conducted. In total, 102 on-line questionnaires were distributed, and 57 responses were collected. The following facts can be drawn from this survey.

- Legal form: $77 \%$ of the social enterprises surveyed $(N=57)$ were registered as non-profit organisations and $18 \%$ as limited-liability companies.

- Age: interestingly, $44 \%(N=25)$ of the social enterprises participating in the research had been founded between three and five years before the survey and $5 \%(N=3)$ less than one year prior to the survey. Only $4 \%$ of the surveyed enterprises $(N=2)$ had existed for at least nine years.

- Fields of activity: given the high diversity of the collected answers, these were grouped in five clusters, namely: education and science, employment of vulnerable groups, economic development, tourism and health care. Analysis of the results revealed that all social enterprises were engaged in several fields of activity, and that all enterprises could be linked to two or more clusters.

- Income: $53 \%$ of the social enterprises surveyed had received funding from the state or a non-governmental organisation. Economic activity constituted a source of income for $70 \%$ of the respondents, and $52 \%$ had more than one funding source. It should also be noted that 
grants represented the only source of income for $19 \%$ of the social enterprises.

- Employment: the number of employees of social enterprises differed according to the enterprise's type of activity. On average, each enterprise employed 9.05 persons, including people with disabilities, internally displaced persons and socially vulnerable people.

- Profit and reinvestment: only $2 \%$ of the surveyed social enterprises $(N=2)$ recorded an annual profit of more than GEL10,000 (€300), while $51 \%(N=29)$ claimed that they had recorded no profit in 2017 (they had either broken even or recorded a loss). It is interesting to note that $23 \%$ of enterprises generated a profit that did not exceed GEL1,000 (€30) in the same year, and a similar share of enterprises reported a profit between GEL1,000 (€30) and GEL5,000 (€150). Interestingly too, $90 \%$ of the enterprises surveyed reinvested all their profits in the social goals defined in their charter.

- Relative weight of social and economic goals: the study also explored the relative weight of the social and economic goals for each social enterprise. Respondents were asked whether, in their social enterprise, social goals prevailed over economic goals; economic goals prevailed over social goals; when the enterprise stood at risk, the achievement of social goals was taken into consideration; when the enterprise stood at risk, the achievement of economic goals was taken into consideration. The results show that, for all the enterprises surveyed, social goals were given priority over economic goals and that, when the enterprise was at risk, the achievement of social goals was given the priority, at the expense of economic goals.

\subsection{Compliance With the EMES Indicators}

In this section, we provide a brief summary of the nine indicators put forward by the EMES International Research Network to describe the ideal-typical social enterprise, and examine the extent to which social enterprises operating in Georgia meet each of these indicators.

\section{Economic Indicators}

- Continuous production/delivery of goods or services: this component, together with social goals, is one of the main elements characterising the functioning of social enterprises. This indicator was fully met by the enterprises surveyed, which were all engaged in the production/delivery of goods/services.

- A certain degree of economic risk: unlike what is the case for public institutions, the financial sustainability of a social enterprise depends on its members and employees' efforts to secure adequate resources. The social enterprises participating in the Georgian study 
were mostly generating financial resources through grants and sales of goods and services.

- A minimum amount of paid work: a social enterprise should have a minimum number of paid workers, while other non-profit organisations might operate by relying on volunteering alone. All the enterprises surveyed had at least one paid worker. The social enterprises analysed also relied on volunteering.

\section{Social Indicators}

- An explicit aim to benefit the community: one of the main goals of a social enterprise is to serve a community or a specific group of people (e.g. vulnerable layers of the population). The primary purpose of the social enterprises that took part in the Georgian survey was the wellbeing of the community, and the majority of these initiatives focused on the production of goods and/or services for marginalised groups.

- An initiative launched by a group of citizens or a civil-society organisation: social enterprises are the result of collective dynamics involving people belonging to a community or to a group that shares a well-defined need or aim. This collective dimension should be maintained over time, although the importance of leadership should not be ignored. All the enterprises surveyed were founded on a collective basis by people sharing a common objective.

- A limited distribution of profits: the primacy of the social goals should be reflected in a constraint on the distribution of profit. However, social enterprises do not include only those organisations that are characterised by a total non-distribution constraint; the social enterprise can also be an organisation that distributes profits but only to a limited extent. Interestingly, $90 \%$ of the surveyed enterprises reinvested all their profits to pursue the social goals set out in their charter. As underlined earlier, the study also highlighted the fact that, in all the participating enterprises, social goals were given priority over economic goals; and when an enterprise was at risk, it still tried to achieve its social goals, at the expense of its economic goals.

\section{Governance-Related Indicators}

- A high degree of autonomy: social enterprises are created by a group of people on the basis of an autonomous project, and they are managed by this group. These enterprises may be dependent on public subsidies, but they should not be managed, directly or indirectly, by public authorities or other organisations (federations, private firms, etc.). As mentioned earlier, the Georgian study revealed that $53 \%$ of social enterprises received funding from the state or a 
non-governmental organisation, but their management and decisionmaking remained independent.

- A decision-making power not based on capital ownership: this indicator mainly refers to the "one member, one vote" principle, or at least to a decision-making process in which the voting power is not distributed according to capital shares on the governing body which has the ultimate decision-making rights. The compliance of Georgian social enterprises with this indicator could not be assessed on the basis of the survey results, as data collected on this topic were not sufficient to allow such analysis.

- A participatory nature, which involves various parties affected by the activity: representation and participation of users or customers, influence of various stakeholders on decision-making and a participative management often constitute important characteristics of social enterprises. On this subject as well, data collected in the framework of the survey were insufficient to assess the extent to which Georgian social enterprises met this indicator.

\subsection{Tentative Typology of Social Enterprises in Georgia}

Based on the discussion earlier and considering three dimensions, namely the nature of the social mission, the type of economic model and the governance structure, a first tentative typology of social enterprise in Georgia can be put forward. This typology consists of the following SE types:

- Work-integration social enterprises: this type of social enterprise corresponds to commercially driven businesses that provide employment opportunities to particular disadvantaged/marginalised groups, such as persons with disabilities, internally displaced persons, youth or the rural poor. It is a quite common practice in Georgia to establish an enterprise in the field of work integration, and it has become an attractive "shield" to attract donor funding.

- Entrepreneurial non-profit organisations: this category includes those non-profit organisations that generate income to achieve their social goals and objectives (Boschee 2001). As evidenced by the research, the vast majority of the surveyed social enterprises are registered under the legal form of NPO. This group also includes organisations providing to marginalised groups public services that are supposed to be delivered by the government.

- Socially oriented businesses: this type of social enterprise refers to companies developing business activities for a primary social purpose or mission (Defourny and Nyssens 2017). In our sample of Georgian social enterprises, one-fifth of enterprises belonged to this type. 
- Cooperatives: this category corresponds to social cooperatives combining the pursuit of their members' interests with the pursuit of the interests of the whole community or of a specific target group (Defourny and Nyssens 2017). In 2013, the Georgian government passed the Law on Agricultural Cooperatives, which defines the purposes of agricultural cooperatives in the following way:

- developing family farming, organising farming households into cooperatives, and strengthening their viability;

- promoting the revival of rural areas and agriculture;

- ensuring the social and economic development of rural areas;

- eliminating rural poverty;

- stopping the rural exodus;

- increasing agricultural productivity, improving competitiveness and raising profitability, as well as developing the national economy;

- promoting the development of biological farming.

\section{Conclusion}

Social entrepreneurship in Georgia has been increasingly developing in recent years, and it is gaining popularity among the population. This chapter discusses the characteristics-identified through qualitative and quantitative research methods-of social enterprises operating in Georgia.

It is interesting to note that there is no specific legal form for social enterprise in Georgia. In theory, social entrepreneurship can take any entrepreneurial or non-entrepreneurial legal form. In practice, however, the vast majority of social enterprises are registered as non-profit organisations or limited-liability companies. Furthermore, no (branch of a) government agency is directly responsible for supporting social entrepreneurs, and no regulations of any of the current ministries mention functions or responsibilities related to social entrepreneurship. There is no state or municipal fund providing subsidies, loans or grants specifically intended for social entrepreneurs or aiming to support their growth.

Based on the results of the research, the following recommendations were identified:

- Improving the legal framework for social enterprises: first of all, it appears necessary to recognise the phenomenon of social entrepreneurship under Georgian law; social enterprises should be subject to specific regulation, and the terms "social enterprise" and "social entrepreneurship" should be defined in the legislation. This can be done in a variety of ways. For example, these terms could be defined 


\section{Giorbelidze}

in the Civil and Tax Codes, or a separate law could be adopted to comprehensively regulate the field of social entrepreneurship. The problem of the legal recognition of social enterprises could also be solved by simultaneous modifying the Company Law and the Civil Code of Georgia. The path chosen among these various alternatives will depend on the model that will best suit the Georgian legal system and will thus be selected by the legislature.

- Developing social-entrepreneurship-related public policies, in particular at the national level: despite the fact that social entrepreneurship is mentioned in some policy documents of several state institutions, it would be good to establish as well an "umbrella" framework to regulate and promote social entrepreneurship at the national level.

- Increasing access to finance: based on the research findings outlined in this chapter, the lack of access to financial resources was identified as one of the obstacles to the development of social enterprise. For the advancement of the field, it is necessary that these initiatives have access to cheap credit.

- Developing the capacity of social entrepreneurs: as stated earlier, the lack of business management skills is a crucial challenge for SE development. With a view to solving this problem, it is essential that social entrepreneurs be systematically trained in marketing, business management, business law and other related disciplines.

- Promoting international cooperation: it is necessary to share information about successful examples of social enterprises to enterprises operating in Georgia as well as to promote cooperation at the international level.

Considering the emerging nature of the SE field in Georgia, the aforementioned steps are crucial for advancing its development and creating an ecosystem to boost the culture of social enterprise in the country.

\section{Notes}

1. See http://iset-pi.ge/index.php/en/iset-economist-blog-2/entry/to-cut-or-notto-cut-shifting-government-priorities.

2. See www.europarl.europa.eu/RegData/etudes/STUD/2017/583123/IPOL_ STU\%282017\%29583123_EN.pdf.

\section{References}

Boschee, J. (2001) "Eight basic principles for nonprofit entrepreneurs", Nonprofit World, Vol. 19, No. 4, pp. 15-18.

Defourny, J. \& Nyssens, S. (2017) “Fundamentals for an international typology of social enterprise models”, Voluntas, Vol. 28, pp. 2469-97. 
Ghauri, P. (2004) "Designing and conducting case studies in international business research", in Marschan-Piekkari, R. \& Welch, C. (eds) Handbook of Qualitative Research Methods for International Business, Cheltenham: Edward Elgar, pp. 109-24.

Lerman, Z. \& Sedik, D. (2014) "Cooperatives in the CIS and Georgia: Overview of legislation”, Policy Studies on Rural Transition, No. 2014-2, FAO Regional Office for Europe and Central Asia.

Millns, J. (2013) "Agriculture and rural cooperation, examples from Armenia, Georgia and Moldova”, Policy Studies on Rural Transition, No. 2013-2, FAO Regional Office for Europe and Central Asia.

Smith, A. (1776) An Inquiry into the Nature and Causes of the Wealth of Nations, London: W. Strahan and T. Cadell.

Yin, R. (1998) "The abridged version of case study research: Design and methods", in Bickman, L. \& Rog, D. (eds) Handbook of Applied Social Research Methods, Thousand Oaks: Sage Publications, pp. 229-59. 